\title{
Low cost palm oil fuel ash based ceramic membranes for oily water separation
}

\author{
Zhong Sheng Tai, Mohd Hafiz Dzarfan Othman *, Siti Khadijah Hubadillah, Ahmad Fauzi Ismail, \\ Mukhlis A Rahman, Juhana Jaafar, Khong Nee Koo, Mohd Haiqal Abd Aziz
}

Advanced Membrane Technology Research Centre, Universiti Teknologi Malaysia, Skudai 81310, Johor, Malaysia

* Corresponding author: hafiz@petroleum.utm.my

\section{Article history}

Received 5 May 2018

Revised 1 June 2018

Accepted 2 July 2018

Published Online 3 December 2018

\begin{abstract}
Ceramic membranes have been gaining so much interest for oily water separation due to their superior characteristics such as good anti-fouling property, superhydrophilic, as well as excellent thermal and chemical stabilities. However, ceramic membranes are very expensive which hinders their uses in large scale applications. Therefore, the aim of our study is to develop a low cost palm oil fuel ash (POFA) based ceramic hollow fiber ceramic membrane for oily water separation application. An asymmetric membrane structure consisting of sponge-like and macrovoid layers were acquired using a combined phase inversion and sintering technique. The membranes were sintered at different temperatures ranging from 1000 to $1150{ }^{\circ} \mathrm{C}$. The sintered membranes were characterized in terms of morphology, mechanical strength, porosity, permeate flux and oil rejection performance. A high oil rejection efficiency of up to $96.0 \%$ was obtained for the membrane sintered at $1050{ }^{\circ} \mathrm{C}$ with the permeate flux of $185.42 \mathrm{~L} / \mathrm{m}^{2} \mathrm{~h}$ at the applied pressure of $3 \mathrm{bar}$. Based on the comparison with other ceramic membranes reported in the literature, it can be concluded that POFA based ceramic hollow fiber membrane showed a comparable performance and thus can be a promising low cost alternative ceramic membrane for oily water separation application.
\end{abstract}

Keywords: Palm oil fuel ash, ceramic membrane, phase inversion, sintering, oily water

\section{INTRODUCTION}

Oily water is a major environmental pollutant and has been the main concern for a range of industries (Gao et al., 2014). There are several conventional methods for oily water treatment namely flotation, gravity settling, coagulation and flocculation. However, these methods have their own disadvantages such as high operating cost, the involvement of toxic compounds, large installation space, generation of secondary pollutants as well as low efficiency in the removal of micron and sub-micron size emulsified oil droplets (Padaki et al., 2015; Pagidi et al., 2014). Membrane separation emerges as an attractive technology in oily water treatment due to several outstanding advantages such as continuous membrane operation with simultaneous pure water and oil resource production, fast operation, high selectivity, compact system design, lower energy consumption and have the ability to work without the addition of chemicals (Madaeni et al., 2012; Vinoth Kumar et al., 2015; Zhu et al., 2016).

Membranes are mainly categorized into two main groups namely polymeric and ceramic membranes which both are used for oily water treatment. Unlike polymeric membranes, ceramic membranes can be applied in the extremely harsh environment due to their superior characteristics in terms of mechanical, thermal and chemical stabilities, superhydrophilicity as well as anti-fouling properties which assure longer lifetime (Cui et al., 2008; Vinoth Kumar et al., 2015). However, the commercialized ceramic membranes (i.e.: alumina, zirconia, titania and silica) are very expensive owing to the high starting ceramic material cost and sintering temperature (Othman et al., 2017). This has restricted the utilization of ceramic membranes in large-scale applications. Therefore, in recent years, there has been an increasing trend in the development of low-cost ceramic membranes with excellent characteristics for various applications.

To date, several attempts in utilizing clay for the fabrication of lowcost ceramic membrane for oily water treatment have been reported. Hubadillah et al. (2017) fabricated the kaolin hollow fiber membrane through phase inversion/sintering technique. The prepared membrane offered high oil rejection rate of 91.2 to $100 \%$ in treating oily wastewater. Nandi et al. (2009) investigated the preparation of circular disk type ceramic membranes using a mixture of low-cost materials such as kaolin, quartz, calcium carbonate, sodium carbonate, boric acid and sodium metasilicate. The membrane achieved high oil rejection efficiency of $96.97 \%$ for $50 \mathrm{mg} / \mathrm{L}$ oil concentration. Besides that, the utilization of waste as one of the starting inorganic materials for ceramic membrane synthesis which was later used for an oily water separation application have also been studied. Suresh et al. (2016) successfully prepared a fly ash based ceramic membrane using a mixture of fly ash, quartz and calcium carbonate as inorganic precursors. A high oil rejection performance of $97 \%$ was obtained at an applied pressure $345 \mathrm{kPa}$ and feed concentration of $176.07 \mathrm{mg} / \mathrm{L}$. Chen et al. (2016) studied the fabrication of mullite membrane using coal fly ash and bauxite doped with $\mathrm{WO}_{3}$ as the sintering aid. High oil rejection performance (99\%) was achieved for the membrane with $20 \mathrm{wt} \%$ of $\mathrm{WO}_{3}$. The utilization of wastes as raw materials for ceramic membrane preparation does not only reduce the production cost but would also minimize environmental pollution through the reduction of disposal waste.

In our study, POFA was used as the starting material for the fabrication of low cost ceramic hollow fiber membrane. POFA is a side product from the burning of palm oil fibers, empty fruit bunches and 
palm kernel shells in palm oil mill boiler at $800-1000{ }^{\circ} \mathrm{C}$ to generate electricity for the crude palm oil extraction process (Altwair \& Kabir, 2010). POFA does not have sufficient nutrient values to be used as fertilizer and is usually disposed to open fields. The open disposal of POFA leads to environmental pollution and is hazardous to human health as the light and small ash particles could pose a serious threat to the human respiratory system. POFA is rich in silica, $\mathrm{SiO}_{2}$ of which the chemical composition varies from 44 to $65 \mathrm{wt} \%$ (Thomas et al., 2017). Therefore, it could be used as the starting ceramic material to fabricate low cost silica-based ceramic membrane for various separation applications. However, the utilization of POFA in membrane fabrication is rarely reported. To our best knowledge, the fabrication of POFA based ceramic membrane for oily water treatment was still yet to be discovered. Therefore, the aim of our study was to develop a low cost POFA based ceramic hollow fiber membrane for the oily water separation process. The membrane was sintered at four different temperatures $\left(1000,1050,1100,1150{ }^{\circ} \mathrm{C}\right)$ which then characterized in terms of morphology, mechanical strength, and porosity. The permeation flux and oily water rejection performance of the membranes were finally evaluated using $1000 \mathrm{mg} / \mathrm{L}$ synthetic oil water.

\section{EXPERIMENTAL}

\section{Materials}

POFA was obtained from a crude oil palm mill in Chaah, Johor, Malaysia which then ground and sieved into finer particles prior to the experiment. N-methyl-pyrrolidone (NMP, Merck), Polyethersulfone (PES, Radel A300, Ameco Performance, USA) and Arlacel P135 (Polyethylene glycol 30-dipolyhydroxystearate, CRODA) were used as a solvent, polymer binder, and dispersant respectively.

\section{Preparation of ceramic suspension}

First, the ceramic suspension was prepared by dissolving $1 \mathrm{wt} \%$ of Arlacel P135 in 56 wt\% of NMP through stirring. This was followed by the gradual addition of $38 \mathrm{wt} \%$ of POFA particles. The mixture was projected to ball milling process in an NQM-2 planetary ball mill at 183 rpm for 48 hours. Then, $5 \mathrm{wt} \%$ of PES was added and the mixture was further ball milled for another 48 hours. After the homogeneous ceramic suspension was obtained, it was vacuum degassed accompanying by gentle stirring for 30 minutes to remove the air bubbles.

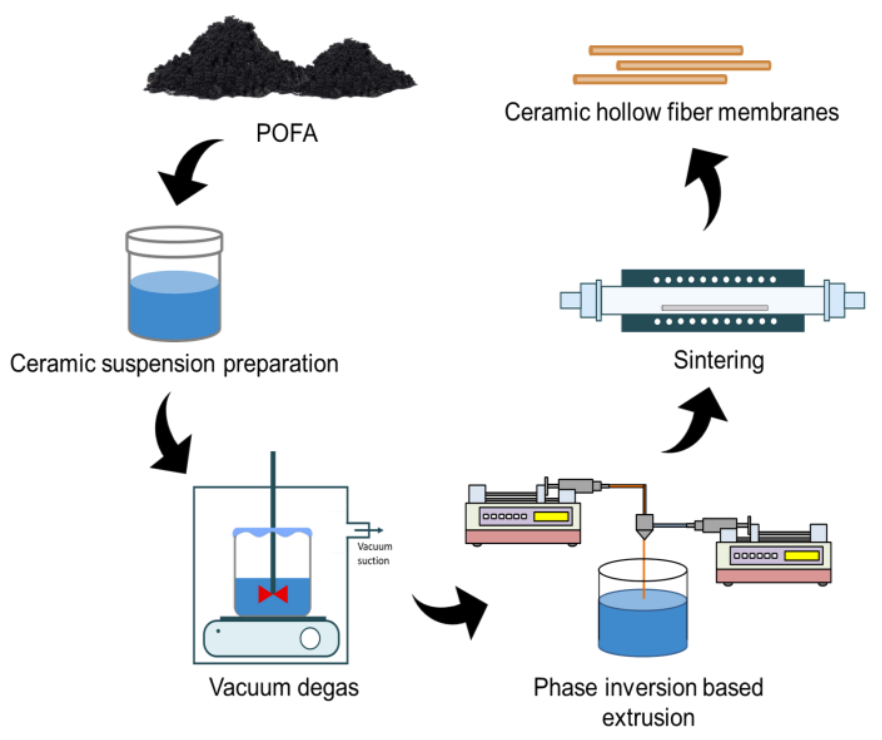

Fig. 1 Schematic diagram for the fabrication of POFA based ceramic hollow fiber membrane.

Fabrication of POFA based ceramic hollow fiber membrane

POFA based ceramic hollow fiber membrane was synthesized through phase inversion based extrusion and sintering technique. After degassing, the ceramic suspension was transferred immediately to a stainless steel syringe and extruded through a tube-in-orifice spinneret with the inner diameter of $0.5 \mathrm{~mm}$ and the outer diameter of $2.8 \mathrm{~mm}$ at a constant rate of $10 \mathrm{~mL} / \mathrm{min}$. Tap water was used as the internal coagulant (bore fluid) and delivered at the flow rate of $9 \mathrm{~mL} / \mathrm{min}$. The extruded suspension fell freely through an air gap distance of $5 \mathrm{~cm}$ into an external coagulant water bath. The obtained fiber precursor was immersed in the water bath overnight to complete phase inversion. The precursor was then cut to shorter lengths and dried at room temperature. Finally, the precursors were sintered in the air atmosphere at various sintering temperatures ranging from 1000 to $1100{ }^{\circ} \mathrm{C}$ by using a tubular furnace (XL-1700, Magna) as follows. The sintering temperature was increased in two stages. At first, the temperature was increased from room temperature to $600{ }^{\circ} \mathrm{C}$ at a heating rate of $2{ }^{\circ} \mathrm{C} / \mathrm{min}$ and then kept constant for 2 hours to eliminate the polymer binder. It was further raised from $600{ }^{\circ} \mathrm{C}$ to the target temperature at $5{ }^{\circ} \mathrm{C} / \mathrm{min}$ and held for 5 hours. Lastly, the temperature was reduced to room temperature at a rate of $5{ }^{\circ} \mathrm{C} / \mathrm{min}$ and POFA based ceramic hollow fiber membrane was obtained. The overall schematic diagram for the fabrication of POFA based ceramic hollow fiber membrane as illustrated in Fig. 1.

\section{Characterization of ceramic membrane}

The cross-sectional morphologies behaviors and thickness of the ceramic hollow fiber membranes were analyzed using scanning electroscopy microscope (SEM, Hitachi Model TM 3000) at different magnification. The samples were coated under vacuum for three minutes before the analysis. The mechanical strength of the membranes was determined through three-point bending test using Instron Model 3342 tensile tester. The bending strength of the membranes (MPa) was calculated by using equation (1)

$$
\sigma_{F}=\frac{8 F L D_{o}}{\pi\left(D_{o}^{4}-D_{i}^{4}\right)}
$$

where $\mathrm{F}$ is the force at which the membrane fractures $(\mathrm{N})$ while $\mathrm{L}, \mathrm{D}_{0}$ and $D_{i}$ are the length, outer and inner diameters of the membrane $(\mathrm{m})$ respectively. The porosity of POFA based ceramic hollow fiber membranes, $\Phi(\%)$ was measured by using Archimedes method as shown in equations (2), (3) and (4).

$$
\begin{aligned}
& V_{p}=\frac{W_{\text {sat }}-W_{\text {dry }}}{\rho_{\text {fluid }}} \\
& V_{b}=\frac{W_{\text {sat }}-W_{\text {sub }}}{\rho_{\text {fluid }}} \\
& \Phi=\frac{V_{p}}{V_{b}} X 100 \%
\end{aligned}
$$

where $V_{p}$ and $V_{b}$ are pore volume and bulk volume $\left(\mathrm{cm}^{3}\right)$ respectively while $\mathrm{W}_{\text {sat }}, \mathrm{W}_{\text {dry }}$, and $\mathrm{W}_{\text {sub }}$ are weight of saturated, dry and submerged membranes $(\mathrm{g})$ respectively. The density of the fluid, $\rho_{\text {fluid }}$ was set to be $1.000 \mathrm{~g} / \mathrm{cm}^{3}$ as water was used for this study. The oil rejection performance of POFA based membrane was evaluated using 1000 $\mathrm{mg} / \mathrm{L}$ synthetic oily water. The synthetic oil water was prepared using cooking oil with the addition of sodium dodecyl sulfate as a dispersant at the ratio of 1:9. The oily water performance tests were conducted at an ambient temperature by using a microfiltration system for 1.5 hours under the pressure of 3 bar. The concentrations of oil particles in the solution were measured through the measurement of absorbance of the oily water before and after filtration using UV-vis spectrophotometer (DR5000, Hach) at the wavelength of $268 \mathrm{~nm}$. The permeate flux, $\mathrm{J}_{\mathrm{v}}$ $\left(\mathrm{L} / \mathrm{m}^{2} \mathrm{~h}\right)$ and oil rejection, $\mathrm{R}(\%)$ were calculated using equations (5) and (6) respectively.

$$
\begin{aligned}
& J_{v}=\frac{V}{A X \Delta t} \\
& R=\frac{C_{f}-C_{p}}{C_{f}}
\end{aligned}
$$

where $\mathrm{V}$ is volume of permeate $\left(\mathrm{m}^{3}\right)$, $\mathrm{A}$ is effective membrane area $\left(\mathrm{m}^{2}\right), \Delta \mathrm{t}$ is time taken (s) whereas $\mathrm{C}_{\mathrm{f}}$ and $\mathrm{C}_{\mathrm{p}}$ are the concentration of oil in the feed and permeate streams respectively. 


\section{RESULTS AND DISCUSSION}

\section{Membrane structure and morphology}

POFA based ceramic hollow fiber membranes were successfully obtained through phase inversion/sintering technique. Fig. 2 depicts the cross-sectional view of membrane precursor and sintered membranes. The inner and outer diameters, as well as the thickness of the membranes, are as shown in Table 1. POFA based membranes consis of asymmetric structures of sponge-like at the outer cross-section region of the membrane and macrovoids originating from the inner surfaces. The sponge-like structure contributes to the mechanical strength of the membranes and separation performance while the macrovoids structure helps to increase the permeability of the membranes (Kingsbury \& Li, 2009; Pagidi et al., 2014; Zhu et al., 2016). Shrinkage of membrane occurred after the membranes were subjected to the sintering process. The radial shrinkage of the hollow fiber membrane increased from 14 to $44 \%$ at higher sintering temperature due to the increasing sintering neck formation through diffusion between ceramic particles (Li et al., 2016).
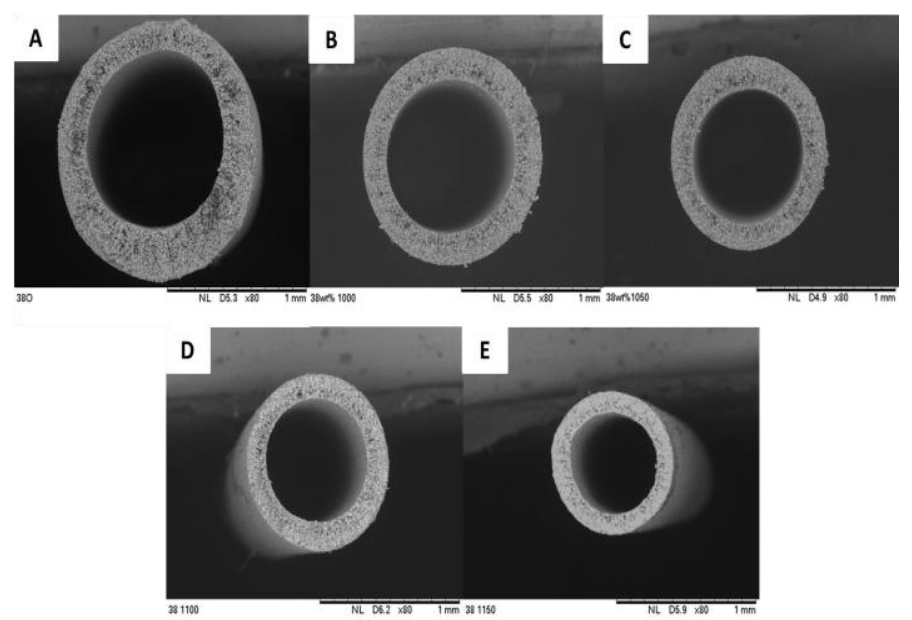

Fig. 2 Overall cross-sectional view of POFA based hollow fiber membranes before $(A)$ and after sintering at different temperatures: $(B)$ $1000^{\circ} \mathrm{C}$; (C) $1050^{\circ} \mathrm{C}$; (D) $1100^{\circ} \mathrm{C}$; (E) $1150^{\circ} \mathrm{C}$.

Table 1 Dimensions of POFA based hollow fiber membranes.

\begin{tabular}{cccc}
\hline $\begin{array}{c}\text { Sintering } \\
\text { Temperature } \\
\left({ }^{\circ} \mathbf{C}\right)\end{array}$ & $\begin{array}{c}\text { Outer } \\
\text { Diameter } \\
(\boldsymbol{\mu m})\end{array}$ & $\begin{array}{c}\text { Inner } \\
\text { Diameter } \\
(\boldsymbol{\mu m})\end{array}$ & $\begin{array}{c}\text { Thickness } \\
(\boldsymbol{\mu m})\end{array}$ \\
\hline Before Sintering & 1500 & 1000 & 500 \\
1000 & 1290 & 917 & 373 \\
1050 & 1140 & 798 & 342 \\
1100 & 1030 & 719 & 311 \\
1150 & 836 & 590 & 246 \\
\hline
\end{tabular}

The microstructure of POFA based hollow fiber membrane precursor and sintered membranes are demonstrated in Fig. 3. Before sintering process, the polymer binder and dispersant were freely distributed among the ceramic particles (Fig. 3A1 and 3A2). After sintering, the polymer binder, dispersant, and carbon were totally burnt off leaving only ceramic particles in the membrane. From Fig. 3, it could also be seen that the grain of the membranes increased in size but reduced in number at elevated sintering temperatures which then led to the densification and shrinkage of the membrane. The thickness of the macrovoid structure reduced from 56 to $41 \%$ when the sintering temperature was increased from 1000 to $1100{ }^{\circ} \mathrm{C}$. When the sintering temperature was further increased to $1150{ }^{\circ} \mathrm{C}$, the surface of the membrane became compact which could be related to the great extent of grain growth and densification of the ceramic membrane (Wang et al., 2016).
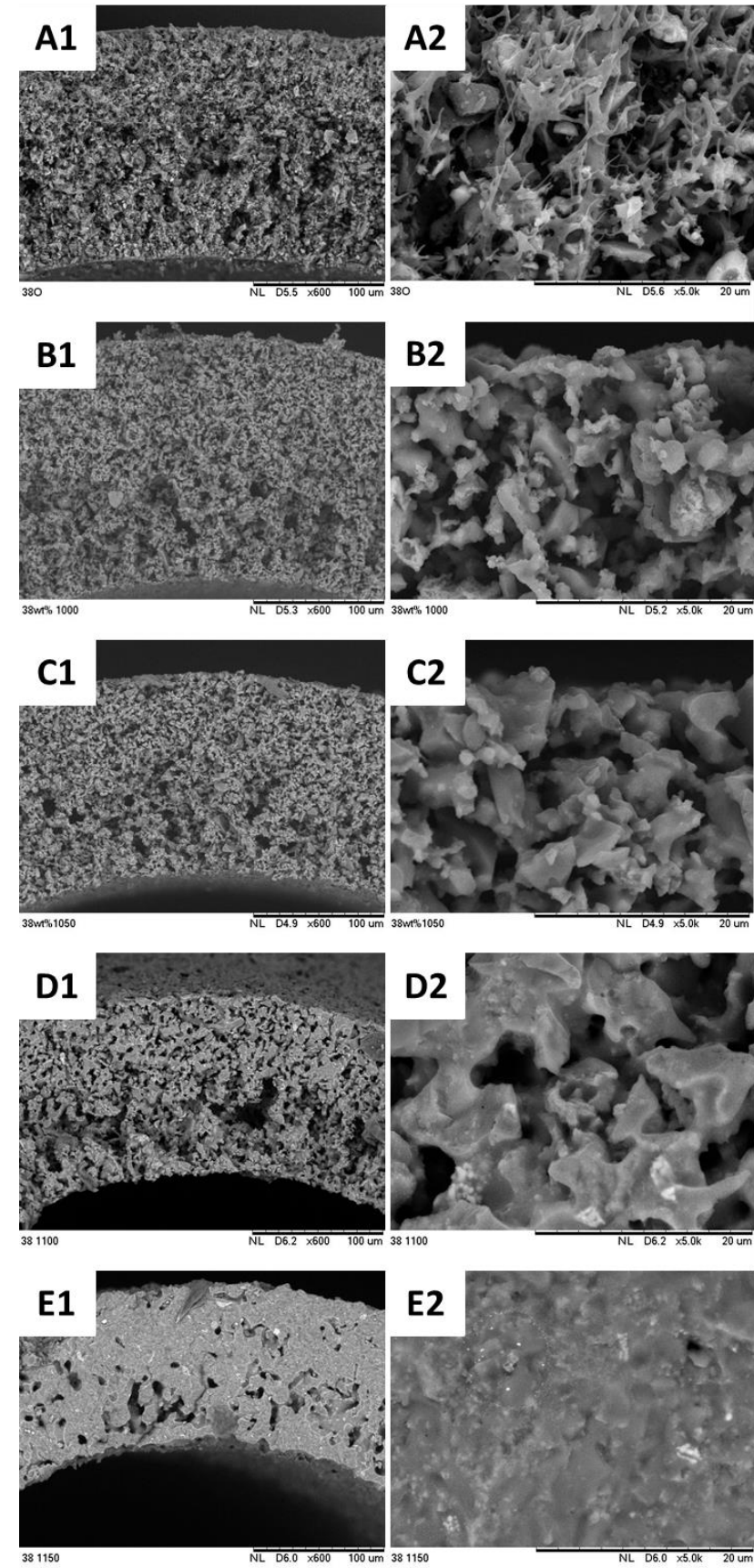

Fig. 3 The microstructural cross-sectional view of POFA based hollow fiber membrane precursor $(A 1, A 2)$ and sintered membranes of different temperatures: (B1, B2) $1000^{\circ} \mathrm{C}$; $(\mathrm{C} 1, \mathrm{C} 2) 1050^{\circ} \mathrm{C}$; (D1, D2) $1100^{\circ} \mathrm{C}$ and (E1, E2) $1150^{\circ} \mathrm{C}$

\section{Mechanical strength of the membrane}

Fig. 4 exhibits the results of three-point bending tests of the lowcost POFA based ceramic hollow fiber membranes sintered at various sintering temperatures. The mechanical strength of the membrane increased from 9.91 to $50.79 \mathrm{MPa}$ with increasing sintering temperature from 1000 to $1150{ }^{\circ} \mathrm{C}$. This was due to the densification of ceramic membrane and a decrease in the macrovoid structure at the elevated sintering temperature. Therefore, the membrane sintered at the highest temperature $\left(1150{ }^{\circ} \mathrm{C}\right)$ possessed the highest mechanical strength. This finding is similar to a study by Wang et al. (2016) which reported the highest mechanical strength for $\beta$-sialon ceramic hollow fiber membrane at the highest studied sintering temperature resulting from the densification of ceramic. Despite the most densified ceramic membrane could offer the highest mechanical strength, it is unfavorably desired for liquid filtration as the extreme low porosity and average pore size would lead to very low or no permeate flux (Adam et al., 2017). POFA based ceramic membranes displayed relatively low 
mechanical strengths which could be due to the high carbon content. During sintering at high temperatures, the carbon was turned into carbon dioxide and evaporate, leaving the voids at the ceramic membranes (Ali et al., 2017). The presence of these voids would lower the mechanical strengths of POFA based ceramic membranes.

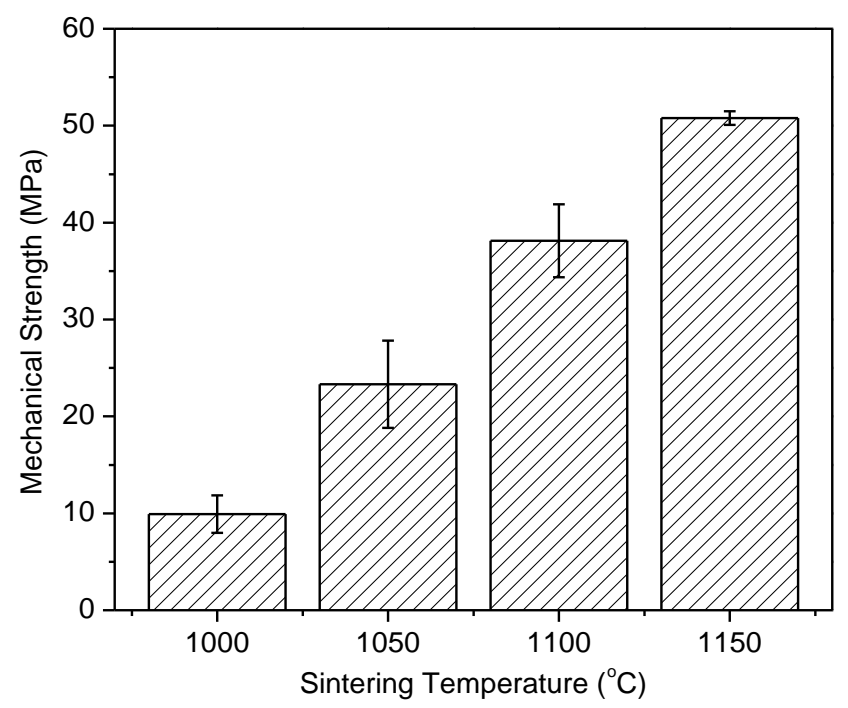

Fig. 4 Mechanical strength of POFA based ceramic membrane sintered at various temperatures.

\section{Porosity of membrane}

The porosity of POFA based ceramic hollow fiber membranes decreased with increasing sintering temperature as shown in Fig. 5. The membrane porosity was the highest $(75.8 \%)$ at the sintering temperature of $1000{ }^{\circ} \mathrm{C}$ and decreased to $47.7 \%$ for the membrane sintered at $1100{ }^{\circ} \mathrm{C}$. As mentioned earlier, the increasing neck growth between the ceramic particles occurred at higher sintering temperature resulting in a closely packed arrangement. This would lead to the reduction of membrane porosity (Mohtor et al., 2017). This has explained the drastic drop in porosity for the membrane sintered at 1100 ${ }^{\circ} \mathrm{C}$ with the significant densification and particles grain growth as shown in Fig. 3D1 and 3D2. A similar trend in decreasing porosity of membrane was also observed in a study by Hubadillah et al. (2017) for kaolin hollow fiber membranes which sintered at different temperatures ranging from 1200 to $1500{ }^{\circ} \mathrm{C}$. The porosity of the POFA based membrane sintered at $1150{ }^{\circ} \mathrm{C}$ was not studied due to the overly dense membrane structure which was not suitable for the liquid separation process (Fig. 3E1 and 3E2).

\section{Performance of membranes}

The permeate flux was correlated with the pore structure of the membrane. Higher permeate flux could be obtained through the more porous membrane structure whereas the dense membrane structure would result in low or no permeate flux (Han et al., 2011). The permeate flux of POFA based ceramic hollow fiber membranes demonstrated a decreasing trend with the increase in sintering temperature as depicted in Fig. 6 . This was because the lower porosity resulting from the pore size shrinkage and densification of membrane structure would restrict the flow of permeate through the membrane. The permeate flux was zero for the membrane sintered at $1100{ }^{\circ} \mathrm{C}$ despite having the porosity of $67.2 \%$. This could be due to the large connection of particle grain causing the presence of extensive dead-end pores which totally hindered the flow of permeate through the membrane.

Fig. 7 illustrates the oil rejection performance of POFA based ceramic hollow fiber membrane using synthetic oily water. The oil rejection of membrane increased with elevated sintering temperature. The denser pore structure with lower porosity and pore size enhanced the sieving mechanism of the membrane towards oily water (Hubadillah et al., 2017). The larger oil particles were refrained from entering the smaller membrane pores and kept at the feed side. It could be observed that high oil rejection performance of 88.6 to $96.0 \%$ was obtained, suggesting that POFA based ceramic hollow fiber membrane could be an excellent alternative membrane for the oil removal separation process.

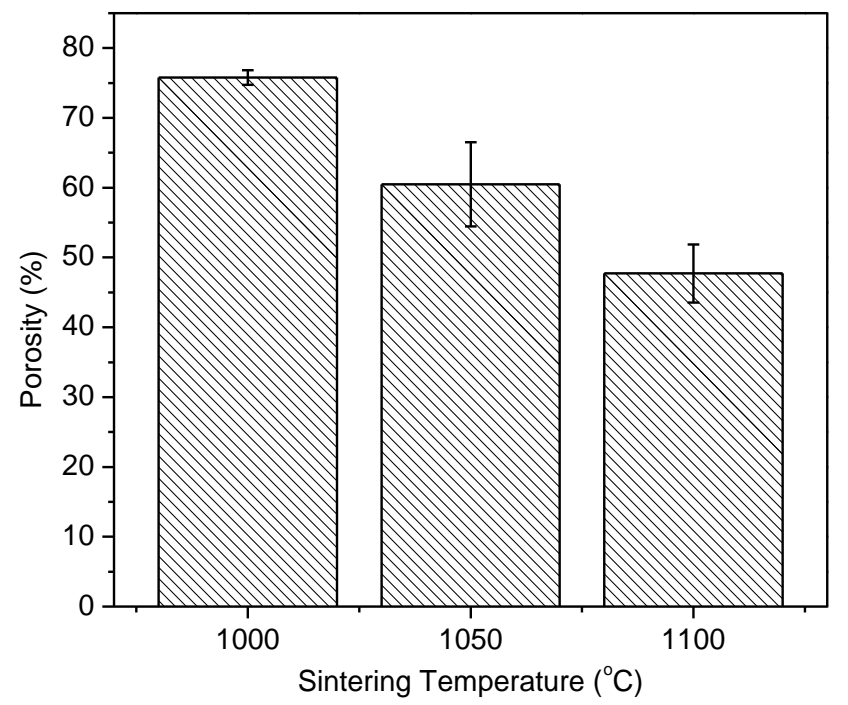

Fig. 5 Porosity of POFA based ceramic hollow fiber membranes sintered at different temperatures.

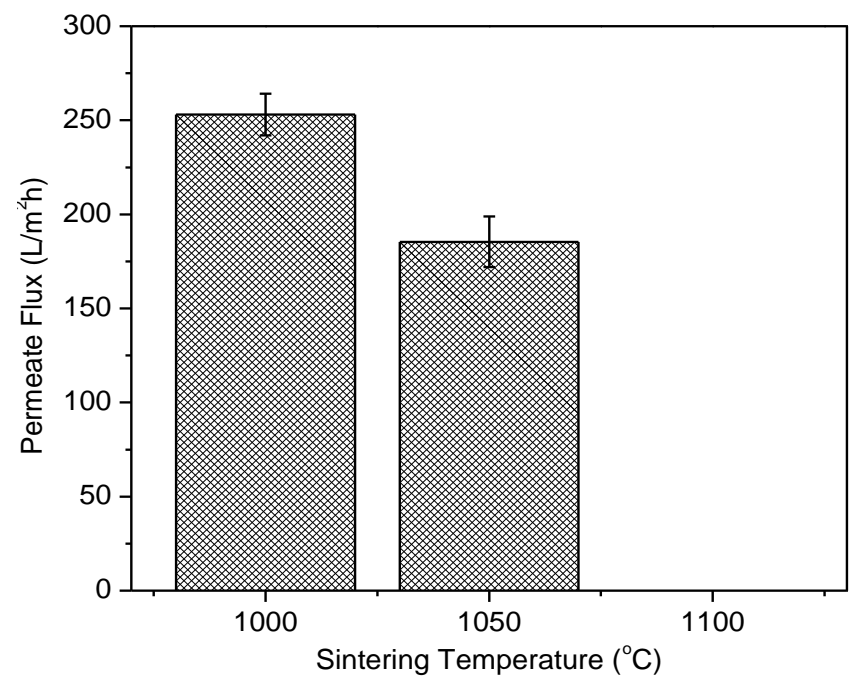

Fig. 6 Permeate flux of POFA based hollow fiber membranes of different sintering temperatures.

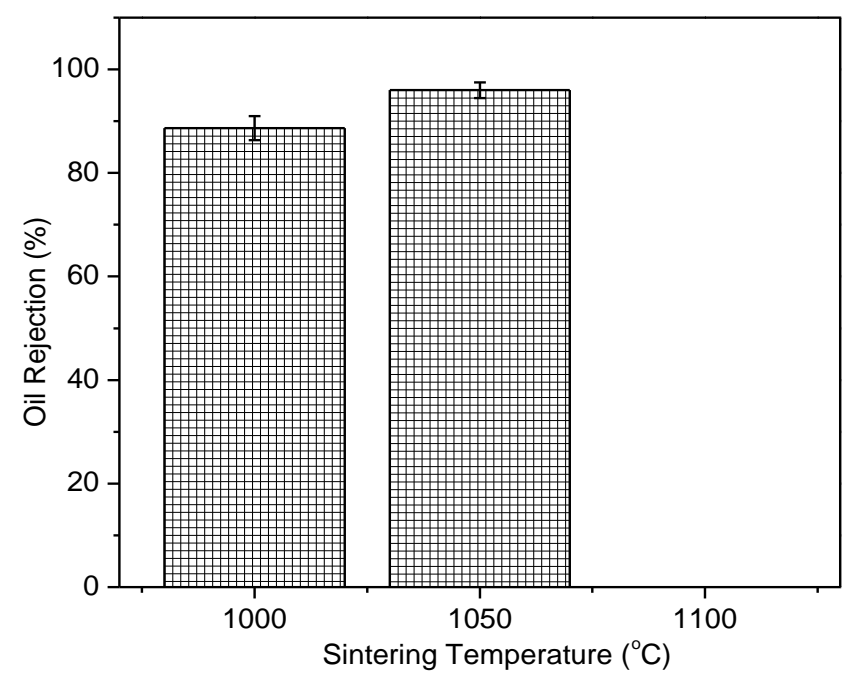

Fig 7 Oil rejection of POFA based ceramic hollow fiber membrane of various sintering temperature. 
Table 2 Potential evaluation of POFA based ceramic membrane with other ceramic membranes in the literature.

\begin{tabular}{|c|c|c|c|c|c|c|}
\hline Membrane Material & $\begin{array}{c}\text { Membrane } \\
\text { Configuration }\end{array}$ & $\begin{array}{l}\text { Pressure } \\
\text { (bar) }\end{array}$ & $\begin{array}{c}\text { Oil } \\
\text { Concentration } \\
(\mathrm{mg} / \mathrm{L})\end{array}$ & $\begin{array}{l}\text { Permeate flux } \\
\left(\mathrm{L} / \mathrm{m}^{2} \mathrm{~h}\right)\end{array}$ & Rejection (\%) & Reference \\
\hline POFA & Hollow Fiber & 3.00 & 1000 & 185.4 & 96.0 & This work \\
\hline Kaolin & Hollow Fiber & 2.00 & - & $<50.0$ & 100.0 & Hubadillah et al. (2017) \\
\hline Mullite- $\mathrm{TiO}_{2}$ & Hollow Fiber & 0.25 & 200 & 37.5 & 97.0 (TOC) & Zhu et al. (2016) \\
\hline$\alpha-\mathrm{Al}_{2} \mathrm{O}_{3}$ & Tubular & 1.25 & 141 (TOC) & 289.8 & 97.8 (TOC) & Abadi et al. (2011) \\
\hline Zeolite/ $\alpha-\mathrm{Al}_{2} \mathrm{O}_{3}$ & Tubular & 0.50 & 100 & 85.0 & 99.5 & Cui et al. (2008) \\
\hline Mixed clay & Tubular & 0.69 & 100 & 113.8 & 99.98 & Vinoth Kumar et al. (2015) \\
\hline Mullite & Tubular & 3.00 & 1000 & 40.0 & 94.0 (TOC) & Abbasi et al. (2010) \\
\hline Fly ash-based & Circular disk & 3.45 & 176 & 936.0 & 96.97 & Suresh et al. (2016) \\
\hline Coal fly ash/bauxite & Circular disk & 1.00 & 250 & 140.4 & $97-99$ & Chen et al. (2016) \\
\hline Mixed clay & Circular disk & 1.65 & 50 & 75.9 & 96.97 & Nandi et al. (2009) \\
\hline
\end{tabular}

Potential evaluation of POFA based ceramic membrane with other ceramic membranes

The oil rejection performance of the POFA based ceramic hollow fiber membrane was evaluated and compared with other ceramic membranes in the works of literature as shown in Table 2. It could be seen that POFA based ceramic membrane has comparatively high oil rejection performance as well as permeate flux for oily water treatment with high oil concentration $(1000 \mathrm{mg} / \mathrm{L})$. It is noteworthy to mention that the membrane for oily water treatment should have high oil rejection efficiency without compromising the permeate flux. In the work investigated by Hubadillah et al. (2017), the kaolin hollow fiber membrane exhibited $100 \%$ of oil rejection but with the low permeate flux of less than $50 \mathrm{mg} / \mathrm{L}$. Despite having the high oil rejection efficiency, the low permeate flux would bring significant adverse impact to the water production rate especially in the large-scale separation process. Therefore, POFA based ceramic hollow fiber membrane could be a promising low cost alternative ceramic membrane for oily water separation applications.

\section{CONCLUSION}

Asymmetric POFA based ceramic hollow fiber membrane has been fabricated using a combined phase inversion and sintering technique. The membrane structure densified and shrunk at the elevated sintering temperature, thus enhancing the mechanical strength of the membrane. However, the membrane porosity experienced a decreasing trend with the increase in sintering temperature, resulting in lower permeate flux. The separation ability of the membrane was evaluated using a 1000 $\mathrm{mg} / \mathrm{L}$ synthetic oily water. The membrane sintered at $1050{ }^{\circ} \mathrm{C}$ achieved the highest oil rejection efficiency of $96.0 \%$ with the permeate flux of $185.42 \mathrm{~L} / \mathrm{m}^{2} \mathrm{~h}$. This indicates that POFA based ceramic hollow fiber membrane can be used as a low cost alternative ceramic membrane for oily water separation applications. However, the optimum membrane demonstrated low mechanical strength probably due to the presence of significant amount of unburnt carbon in the POFA powders. Hence, enhancement pretreatment technique is currently being studied in our lab to improve the purity of metal oxides in POFA in order to achieve stronger mechanical strength for the separation applications.

\section{ACKNOWLEDGEMENT}

The authors gratefully acknowledge the financial support from the Ministry of Education Malaysia under the Higher Institution Centre of Excellence Scheme (Project number: R.J090301.7846.4J192), University Teknologi Malaysia under the Research University Grant Tier 1 (Project number: Q.J130000.2546.12H25) and Kurita Water and Environment Foundation Research Grant (Project number: 16P022).

\section{REFERENCES}

Abadi, S. R. H., Sebzari, M. R., Hemati, M., Rekabdar, F., \& Mohammadi, T (2011). Ceramic membrane performance in microfiltration of oily wastewater. Desalination, 265(1), 222-228. doi: https://doi.org/10.1016/ j.desal.2010.07. 055

Abbasi, M., Mirfendereski, M., Nikbakht, M., Golshenas, M., \& Mohammadi, T. (2010). Performance study of mullite and mullite-alumina ceramic MF membranes for oily wastewaters treatment. Desalination, 259(1), 169-178. doi: https://doi.org/10.1016/j.desal.2010.04.013

Adam, M. R., Hafiz Puteh, M., Rahman, M., Jaafar, J., \& Othman, M. H. (2017). A fabrication of a low-cost zeolite based ceramic membrane via phase inversion and sintering technique. Malaysian Journal of Analytical Sciences, 21, 391-401. doi: 10.17576/mjas-2017-2102-14

Ali, M. S., Hanim, M. a. A., Tahir, S. M., Jaafar, C. N. A., Mazlan, N. \& Amin Matori, K. (2017). The effect of commercial rice husk ash additives on the porosity, mechanical properties, and microstructure of alumina ceramics. Advances in Materials Science and Engineering, 2017, 10. doi: 10.1155/ $2017 / 2586026$

Altwair, N. M., \& Kabir, S. (2010). Palm Oil Fuel Ash (POFA) An environmentally-friendly supplemental cementitious material for concrete production. International Conference on Material Science and 64th RILEM Annual Week - MATSCI, 6-10 September, Aachen, Germany, 234247

Chen, M., Zhu, L., Dong, Y., Li, L., \& Liu, J. (2016). Waste-to-resource strategy to fabricate highly porous whisker-structured mullite ceramic membrane for simulated oil-in-water emulsion wastewater treatment. ACS Sustainable Chemistry \& Engineering, 4(4), 2098-2106. doi: 10.1021/ acssuschemeng. 5b01519

Cui, J., Zhang, X., Liu, H., Liu, S., \& Yeung, K. L. (2008). Preparation and application of zeolite/ceramic microfiltration membranes for treatment of oil contaminated water. Journal of Membrane Science, 325(1), 420-426. doi: https://doi.org/10.1016/j.memsci.2008.08.015

Gao, S., Shi, Z., Wen Zhang, B., Zhang, F., \& Jin, J. (2014). Photo-induced superwetting single-walled carbon nanotube/ $\mathrm{TiO}_{2}$ ultrathin network films for ultrafast separation of oil-in-water emulsions. ACS Nano, 8(6), 6344 6352. doi: 10.1021/nn501851a

Han, L.-F., Xu, Z.-L., Cao, Y., Wei, Y.-M., \& Xu, H.-T. (2011). Preparation, characterization and permeation property of $\mathrm{Al}_{2} \mathrm{O}_{3}, \mathrm{Al}_{2} \mathrm{O}_{3}-\mathrm{SiO}_{2}$ and $\mathrm{Al}_{2} \mathrm{O}_{3}$-kaolin hollow fiber membranes. Journal of Membrane Science, 372(1), 154-164. doi: https://doi.org/10.1016/j.memsci.2011.01.065

Hubadillah, S. K., Othman, M. H. D., Harun, Z., Ismail, A. F., Rahman, M. A. Jaafar, J., Jamil, S. M., \& Mohtor, N. H. (2017). Superhydrophilic, low cost kaolin-based hollow fibre membranes for efficient oily-wastewater separation. Materials Letters, 191, 119-122. doi: 10.1016/j.matlet. 2016.12. 099

Kingsbury, B. F. K., \& Li, K. (2009). A morphological study of ceramic hollow fibre membranes. Journal of Membrane Science, 328(1-2), 134-140. doi: 10.1016/j.memsci.2008.11.050

Li, L., Chen, M., Dong, Y., Dong, X., Cerneaux, S., Hampshire, S., Cao, J., Zhu, L., Zhu, Z., \& Liu, J. (2016). A low-cost alumina-mullite composite hollow fiber ceramic membrane fabricated via phase-inversion and sintering method. Journal of the European Ceramic Society, 36(8), 2057 2066. doi: http://dx.doi.org/10.1016/j.jeurceramsoc.2016.02.020

Madaeni, S. S., Ahmadi Monfared, H., Vatanpour, V., Arabi Shamsabadi, A., Salehi, E., Daraei, P., Laki, S., \& Khatami, S. M. (2012). Coke removal from petrochemical oily wastewater using $\gamma-\mathrm{Al}_{2} \mathrm{O}_{3}$ based ceramic microfiltration membrane. Desalination, 293(Supplement C), 87-93. doi: https://doi.org/ 10.1016/j.desal.2012.02.028

Mohtor, N. H., Othman, M. H. D., Ismail, A. F., Rahman, M. A., Jaafar, J., \& Abdulhameed, M. A. (2017). Investigation on the effect of sintering temperature on kaolin hollow fiber membrane for water application. Jurnal Teknologi, 79(1-2), 47-51. doi: http://dx.doi.org/10.11113/jt.v79.10436

Nandi, B. K., Uppaluri, R., \& Purkait, M. K. (2009). Treatment of Oily Waste Water Using Low-Cost Ceramic Membrane: Flux decline mechanism and economic feasibility. Separation Science and Technology, 44(12), 28402869. doi: 10.1080/01496390903136004 
Othman, M. H. D., Hubadillah, S. K., Adam, M. R., Ismail, A. F., Rahman, M. A., \& Jaafar, J. (2017). Silica-based hollow fiber membrane for water treatment. In K. Ghasemzadeh (Ed.), Current Trends and Future Developments on (Bio-) Membranes (pp. 157-180). Amsterdam, Netherlands: Elsevier.

Padaki, M., Surya Murali, R., Abdullah, M. S., Misdan, N., Moslehyani, A., Kassim, M. A., Hilal, N., \& Ismail, A. F. (2015). Membrane technology enhancement in oil-water separation. A review. Desalination, $\begin{array}{llll}357 \text { (Supplement } & \text { C), } & \text { 197-207. }\end{array}$ https://doi.org/10.1016/j.desal.2014.11.023

Pagidi, A., Saranya, R., Arthanareeswaran, G., Ismail, A. F., \& Matsuura, T. (2014). Enhanced oil-water separation using polysulfone membranes modified with polymeric additives. Desalination, 344(Supplement C), 280-288. doi: https://doi.org/10.1016/j.desal.2014.03.033

Suresh, K., Pugazhenthi, G., \& Uppaluri, R. (2016). Fly ash based ceramic microfiltration membranes for oil-water emulsion treatment: Parametric Optimization using response surface methodology. Journal of Water Process Engineering, 13(Supplement C), 27-43. doi https://doi.org/10.1016/ j.jwpe.2016.07.008

Thomas, B. S., Kumar, S., \& Arel, H. S. (2017). Sustainable concrete containing palm oil fuel ash as a supplementary cementitious material - A review. Renewable and Sustainable Energy Reviews, 80, 550-561. doi: http:// dx.doi.org/10.1016/j.rser.2017.05.128

Vinoth Kumar, R., Kumar Ghoshal, A., \& Pugazhenthi, G. (2015). Elaboration of novel tubular ceramic membrane from inexpensive raw materials by extrusion method and its performance in microfiltration of synthetic oily wastewater treatment. Journal of Membrane Science, 490(Supplement C), 92-102. doi: https://doi.org/10.1016/j.memsci.2015.04.066

Wang, J.-W., Li, L., Zhang, J.-W., Xu, X., \& Chen, C.-S. (2016). $\beta$-sialon ceramic hollow fiber membranes with high strength and low thermal conductivity for membrane distillation. Journal of the European Ceramic Society, 36(1), 59-65. doi: http://dx.doi.org/10.1016/j.jeurceramsoc .2015 .09 .027

Zhu, L., Chen, M., Dong, Y., Tang, C. Y., Huang, A., \& Li, L. (2016). A lowcost mullite-titania composite ceramic hollow fiber microfiltration membrane for highly efficient separation of oil-in-water emulsion. Water Research, 90(Supplement C), 277-285. doi: https://doi.org/10.1016/ j.watres.2015.12. 035 